\section{Cureus}

Received 05/24/2017

Review began 05/31/2017

Review ended 07/11/2017

Published 07/16/2017

(c) Copyright 2017

Cohen et al. This is an open access article distributed under the terms of the Creative Commons Attribution License CC-BY 3.0., which permits unrestricted use, distribution, and reproduction in any medium, provided the original author and source are credited.

\title{
Dramatic Response of an Aggressive Chest Wall Recurrence to Hyperthermia, Radiation, and Chemotherapy
}

Justin Cohen ${ }^{1}$, Stephanie Rice ${ }^{2}$, Tejan Diwanji ${ }^{3}$, Steven J. Feigenberg ${ }^{4}$, Zeljko Vujaskovic ${ }^{2}$

1. Department of Radiation Oncology, University of Maryland School of Medicine 2. Department of Radiation Oncology, University of Maryland Medical Center 3. Radiation Oncology, University of Maryland School of Medicine 4. Department of Radiation Oncology, University of Maryland School of Medicine, Baltimore, USA

$\square$ Corresponding author: Justin Cohen, justin.cohen@som.umaryland.edu Disclosures can be found in Additional Information at the end of the article

\section{Abstract}

Hyperthermia has been demonstrated to be an effective adjuvant oncological treatment modality in combination with chemotherapy and/or radiation. Published data have demonstrated that the addition of hyperthermia can improve local control for breast cancer chest wall recurrences. We present a patient with a very aggressive estrogen receptor-negative, progesterone receptor-negative, HER2/neu receptor-negative chest wall recurrence status-post a right modified radical mastectomy. Despite having metastatic disease, in an attempt to achieve local control and provide palliation, she was treated with hyperthermia, radiation, and chemotherapy. A near complete resolution of her chest wall recurrence in a very short time period was seen with a significant improvement in her symptoms. While she unfortunately succumbed to her disease shortly thereafter, the local control that our treatment offered her allowed her quality of life to improve significantly near the end of her life.

Categories: Radiation Oncology, Oncology

Keywords: hyperthermia, hyperthermia and chemotherapy, chest wall recurrence, hyperthermia and chest wall recurrence, non-invasive hyperthermia, localized hyperthermia and external beam $\mathrm{x}$ irradiation

\section{Introduction}

Chest wall recurrences are a source of significant morbidity for breast cancer patients. Bleeding, ulceration, extreme pain, and psychological distress are common. Though many patients who present with a chest wall recurrence already have distant metastatic disease, achieving local control for palliation should be attempted if possible. Moderate hyperthermia $\left(40^{\circ} \mathrm{C}-43^{\circ} \mathrm{C}\right)$ has been demonstrated to be a chemo and radiosensitizer in in vitro and in vivo studies. Among other cancer types, there is evidence that hyperthermia can be used to improve local control in combination with radiation and/or chemotherapy for chest wall recurrences.

\section{Case Presentation}

A 38-year-old female with an unremarkable past medical and family history presented to the emergency department (ED) with a lump in the upper outer quadrant of her right breast. She admitted to noting this lump one year prior to presentation. Ultrasound examination revealed a $2.4 \times 2.0 \times 2.5 \mathrm{~cm}$ mass, along with three enlarged right axillary lymph nodes. A core biopsy revealed a poorly differentiated, estrogen receptor-negative, progesterone receptor-negative,

How to cite this article

Cohen J, Rice S, Diwanji T, et al. (July 16, 2017) Dramatic Response of an Aggressive Chest Wall

Recurrence to Hyperthermia, Radiation, and Chemotherapy. Cureus 9(7): e1479. DOI 10.7759/cureus. 1479 
HER2/neu-negative (triple negative), infiltrating ductal carcinoma (IDC) with a Ki-67 of 80\%. Biopsy of the right axilla was negative for disease, although this was felt to be a false negative. A bone scan and computerized tomography (CT) scan of the chest, abdomen, and pelvis with contrast were negative for signs of distant metastatic disease, making her initial clinical stage T2N1M0 Stage IIB IDC.

After multidisciplinary review, she began neoadjuvant chemotherapy with Adriamycin and Cytoxan prior to surgical resection due to her triple negative disease and high proliferation index. She was able to complete three cycles but failed to follow-up for her fourth cycle. She presented back to the surgical oncologist, and on a review of her imaging, it was noted that there had been some shrinkage of the tumor initially. However, due to concern for growth after cycle 3, surgical resection was planned. She underwent breast cancer (BRCA) genetic testing, which was negative, so she proceeded with a right modified radical mastectomy with axillary dissection. The pathology revealed an $8 \mathrm{~cm}$ mass with two out of four nodes positive for metastatic disease with extracapsular extension (ECE). Distance from the closest margin was 1 $\mathrm{mm}$. The final pathologic staging was pT3N1a.

After sufficient healing, further adjuvant chemotherapy was planned. However, nine weeks following surgery, she presented to her surgeon with a swelling of the superior flap, first appearing five to six days prior and initially feeling like a "bump". While this new swelling enlarged over the five to six days prior to presentation, the overlying skin had become shiny and the area had become tender. On physical exam, she was noted to have a $3 \mathrm{~cm}$ wellcircumscribed mass, which was warm, erythematous, and extremely tender to palpation. An ultrasound revealed a $2.4 \mathrm{~cm}$ complex heterogeneous mass with no drainable collection. There was a concern for this being a chest wall recurrence; however, owing to the very short time period that it took to arise, it was thought to be infectious. Therefore, the patient was given a one week trial of cephalexin and instructed to follow-up to evaluate whether the swelling had responded to the antibiotics or whether further investigation was warranted.

One week later, she presented back with no improvement in her symptoms. Ultrasound was repeated with no apparent change. An incisional biopsy revealed a recurrence of her cancer. After this resection, the surgeon felt he could not obtain negative margins and referred her to radiation oncology.

She presented to a radiation oncologist approximately three weeks after her chest wall recurrence (Figure 1). She complained of worsening right-sided breast pain, which she rated as $7 / 10$ in severity, with radiation to her axilla and down to her fingertips. She was taking hydrocodone, Dilaudid, and Lyrica without any relief. On CT simulation, the mass measured 6 $\mathrm{cm}$ in longitudinal dimension with multifocal disease throughout the breast (Figure 2). A chest, abdominal, and pelvic CT performed five days later showed an increase in the size of the mass to $6 \times 5.7 \mathrm{~cm}$, multifocal and involving the pectoralis musculature, as well as noting mediastinal, hilar and subcarinal nodal disease, along with liver metastases.

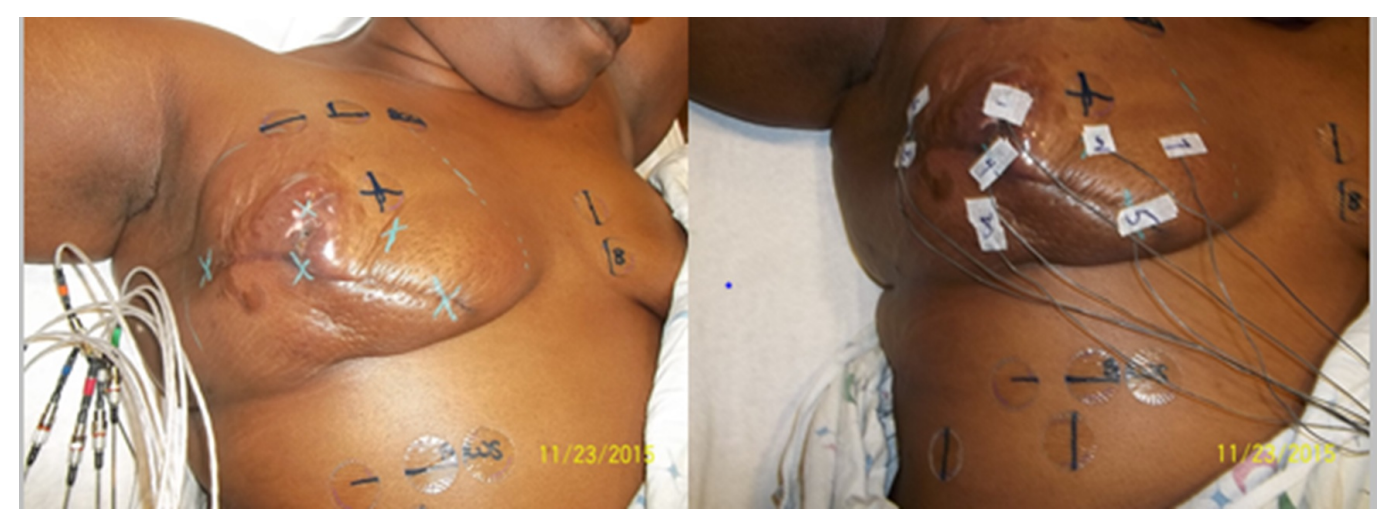




\section{Cureus}

\section{FIGURE 1: Simulation summary images of chest wall recurrence at time of treatment initiation shows skin discoloration and multiple satellite nodules}

This mass lesion grew aggressively between surgical resection and surgical follow-up.

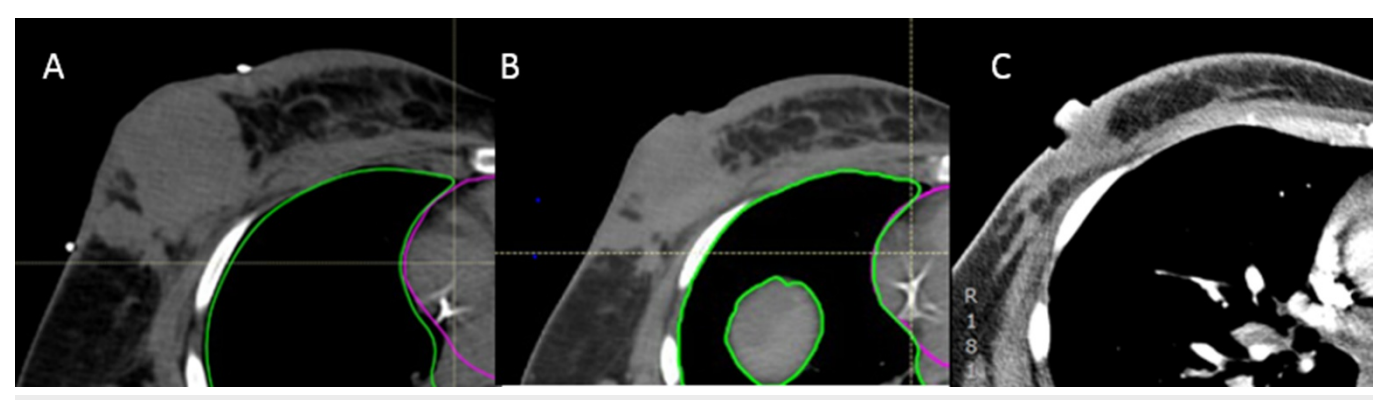

\section{FIGURE 2: Representative images of chest wall mass}

A) CT simulation, B) three weeks into treatment, and C) three weeks after treatment. She developed significant pain relief by the time image B was obtained and had almost complete regression of her tumor (total $<2 \mathrm{~cm}$ ) at the time of her diagnostic CT scan three weeks after treatment.

For local control and palliation of her symptoms, the initial plan was to proceed with radiation to a dose of 70 Gray (Gy) in 35 fractions (2 Gy/fraction) to the gross chest wall disease with a simultaneous integrated boost of $56 \mathrm{~Gy}$ in 35 fractions (1.6 Gy/fraction) to the right chest wall, axillary, supraclavicular, and internal mammary lymph nodes. However, when metastatic disease was seen, the plan was brought back to the multidisciplinary discussion where we decided to add capecitabine as opposed to offering a more abbreviated radiation schedule. As published studies have demonstrated an improvement in local control when hyperthermia is added for chest wall disease [1-2], she was treated with external thermal therapy (ETT) twice weekly to the recurrence.

Shortly after initiating treatment, she developed back pain. A magnetic resonance imaging (MRI) scan and bone scan revealed metastatic lesions to the thoracic spine at T6 and the right posterior 10th rib, which were then treated with 1 fraction of $8 \mathrm{~Gy}$ which she tolerated well.

Already by the third fraction of her chest wall and comprehensive nodal irradiation, she had a dramatic improvement in pain at the site of the chest wall recurrence. Her chest wall pain substantially decreased between weeks 2 and 3, at which time she started to develop radiation dermatitis. She was started on Silvadene for skin breakdown, and her pain became associated with skin irritation rather than the mass, which continuously decreased in size during the course of radiation treatments. Figure 2 demonstrates the continual decrease in the size of her chest wall mass during her treatment course. She was initially tolerating treatment fairly well, but due to the development of skin desquamation and Grade 3 dermatitis, treatment was stopped after receiving $58 \mathrm{~Gy}$ and completing 12 of the 14 planned hyperthermia treatments.

Though already metastatic, there had been dramatic treatment response to the chest wall recurrence. In total, her overall tumor burden decreased to $<2 \mathrm{~cm}$ from $9 \mathrm{~cm}$ with multifocal disease at the time of the CT simulation. Clinically, her tumor regressed significantly 


\section{Cureus}

throughout treatment, and she tolerated this treatment well with the expected skin reaction, given her daily bolus to ensure adequate skin dosing.

Approximately three weeks following completion of treatment, she presented to the emergency department with a two to three-week history of worsening shortness of breath, chest, and abdominal pain. Review of her breast imaging showed significant breast tumor response with the tumor now in a single focus measuring $<2 \mathrm{~cm}$ with much less skin thickening and no obvious involvement of the pectoralis musculature. Unfortunately, the scan also showed diffuse bony and lung metastatic disease. She was septic with severe lactic acidosis. Soon after presentation, her status worsened and she succumbed to her disease (see Table 1 for a timeline of events).

\begin{tabular}{|c|c|c|c|}
\hline IIme & $\begin{array}{l}\text { Reason for } \\
\text { presentation/symptoms }\end{array}$ & Diagnosis & Treatment \\
\hline $\begin{array}{l}\text { Initial } \\
\text { presentation }\end{array}$ & $\begin{array}{l}\text { Presented with lump in } \\
\text { right breast }\end{array}$ & $\begin{array}{l}\text { Poorly } \\
\text { differentiated } \\
\text { IDC, T2N1 }\end{array}$ & \\
\hline $\begin{array}{l}7 \text { months } \\
\text { after initial } \\
\text { presentation }\end{array}$ & & & $\begin{array}{l}\text { Completed } 3 \text { out of } 5 \text { planned } \\
\text { cycles of neoadjuvant chemo }\end{array}$ \\
\hline $\begin{array}{l}9 \text { months } \\
\text { after initial } \\
\text { presentation }\end{array}$ & & pT3N1a & $\begin{array}{l}\text { Right modified radical mastectomy } \\
\text { with axillary dissection }\end{array}$ \\
\hline $\begin{array}{l}9 \text { weeks } \\
\text { postop }\end{array}$ & $\begin{array}{l}\text { Six-day history of a } \\
\text { growing tender mass on } \\
\text { superior flap }\end{array}$ & $\begin{array}{l}\text { Thought to be } \\
\text { infectious }\end{array}$ & One-week course of Keflex \\
\hline $\begin{array}{l}11 \text { weeks } \\
\text { postop }\end{array}$ & & $\begin{array}{l}\text { Incisional biopsy } \\
\text { showing } \\
\text { recurrence }\end{array}$ & \\
\hline $\begin{array}{l}12 \text { weeks } \\
\text { postop }\end{array}$ & $\begin{array}{l}\text { Presented to Radiation } \\
\text { Oncology }\end{array}$ & $\begin{array}{l}\text { CT simulation } \\
\text { performed, } \\
\text { showed } 6 \mathrm{~cm} \\
\text { mass }\end{array}$ & $\begin{array}{l}\text { Planned to proceed with } 70 \text { Gy to } \\
\text { gross chest wall disease and } 56 \text { Gy } \\
\text { to the right chest wall and } \\
\text { comprehensive nodes and } \\
\text { concurrent hyperthermia }\end{array}$ \\
\hline $\begin{array}{l}13 \text { weeks } \\
\text { postop }\end{array}$ & $\begin{array}{l}\text { Diagnostic } \mathrm{Cl} \text { to rule out } \\
\text { metastatic disease }\end{array}$ & $\begin{array}{l}\text { Mediastinal, hilar, } \\
\text { and subcarinal } \\
\text { nodal disease, } \\
\text { along with liver } \\
\text { metastases }\end{array}$ & Started on Capecitabine \\
\hline
\end{tabular}

\section{Outcome}

Initial shrinkage but

growth after $3^{\text {rd }}$

cycle, planned for

surgery

Non-concerning

organizing

hematoma on

inferior flap,

otherwise normal

postop recovery

No shrinkage of mass and worsening local tenderness

Shrinkage of CWR to less than $2 \mathrm{~cm}$, 


\section{Cureus}

14 weeks

postop

15 weeks

postop

19 weeks

postop

23 weeks

postop
Presented to ED with

SOB, chest, and

abdominal pain
Initiated radiotherapy and

hyperthermia treatments

MRI and bone

scans reveal

spine and rib

metastatic

lesions

Stopped treatment after $58 \mathrm{~Gy}$ and

$12 / 14$ hyperthermia treatments to

the breast due to dermatitis and

skin desquamation improvement pain

associated with

CWR

Palliation of back

pain

Died from respiratory

failure 3 days after

presentation to ED

\section{TABLE 1: Timeline of Events}

IDC: invasive ductal carcinomas; CT: computed tomography; CWR: chest wall recurrence; MRI: magnetic resonance imaging; ED: emergency department; SOB: shortness of breath

\section{Discussion}

There are multiple biological mechanisms behind hyperthermia-induced chemo and radiosensitization. One is that hyperthermia induces vasodilation, which results in more blood and oxygen delivery to the otherwise hypoxic regions of the tumor. This enhances the tumoricidal effect of chemotherapy and radiation. The increase in perfusion also results in increased chemo delivery to the tumor [3]. Additionally, hyperthermia impairs deoxyribonucleic acid (DNA) repair proteins, thus preventing tumor cells from repairing their DNA following sub-lethal doses of chemo and radiation. Hyperthermia has also been shown to have direct cytotoxic effects, inducing apoptosis in tumor cells - even in the absence of chemo and radiation. There is also evidence that hyperthermia augments an enhanced immune response against tumor cells. Additionally, hyperthermia makes the otherwise radioresistant S phase of the cell cycle radiosensitive. Hyperthermia can also inhibit tumor angiogenesis by preventing the expression of vascular endothelial growth factor (VEGF) [4].

The two ways that moderate hyperthermia can be delivered to superficial tumors is through capacitive heating and electromagnetic radiative heating. In capacitive heating, the patient lies on a treatment table that has an embedded electrode. A second electrode is placed on the patient at the site of the superficial tumor. A current runs between the two electrodes, heating the tumor. In radiative heating, an antenna coupled to a water bolus is used to deliver microwaves to the tumor. A study that employed the use of hyperthermia treatment planning to compare capacitive and radiative heating found that radiative heating was superior to capacitive heating. They found that capacitive heating resulted in hot spots within fat, thus impeding the ability to get to a therapeutic temperature within the tumor. With radiative heating, the power absorption with fat was lower, thus minimizing treatment limiting hot spots [5].

At our institution, patients are treated with microwave radiative hyperthermia using the Food 
and Drug Administration (FDA) approved BSD-500 PC system (Pyrexar Medical, Salt Lake City, UT). Sessions are usually twice a week during radiation treatment, lasting 45-60 minutes. The temperature is raised as high as the patient can tolerate, with a maximum allowable temperature of $44^{\circ} \mathrm{C}$ (preferably in the range of $40-43^{\circ} \mathrm{C}$ ).

The local control benefit for chest wall recurrences treated with hyperthermia is well described. In 1996, Vernon, et al. published a meta-analysis of 306 patients from five Phase III trials comparing radiation, plus hyperthermia, to radiation alone [1]. Hyperthermia increased complete response (CR) rates from $41 \%$ to $59 \%$. A more pronounced difference was noted when a lower dose of radiation was administered due to previous irradiation (57\% vs. 31\%). Thermal blistering was observed in $11 \%$ of patients. In 2005, Jones, et al. published data from a Phase III trial of 109 patients with superficial tumors, randomized to receive hyperthermia, plus radiation, or radiation alone [2]. In patients who were not previously irradiated, in the hyperthermia arm, 65\% had a CR whereas, in the radiation alone arm, 51\% had a complete response. The difference between the two treatment arms was even more pronounced in previously irradiated patients. In the hyperthermia arm, $68 \%$ of patients had a CR whereas, in the radiation alone arm, $24 \%$ had a complete response. The majority of patients enrolled in this study had chest wall recurrences. Hyperthermia was generally well tolerated. There were 26 burns among 56 patients (46\%) who received 600 hyperthermia treatments (4.3\%). The majority of these thermal burns were first degree.

Since some chest wall recurrences happen in the setting of metastatic disease, studies have not demonstrated an overall survival (OS) benefit to hyperthermia. However, the morbidity associated with local recurrence warrants consideration of its use for local control benefit. Our patient had a very aggressive recurrence causing significant pain and distress. Metastatic disease was identified prior to initiating therapy. Nonetheless, she was treated with radiation, chemotherapy, and hyperthermia, which resulted in a near complete resolution of her chest wall recurrence in a very short time period and a significant improvement in her symptoms. While she did succumb to her disease, the local control that our aggressive multimodality treatment offered her allowed her quality of life to improve significantly near the end of her life. This clinical endpoint is incredibly significant for patients with terminal disease, and improvements in quality of life should be emphasized in these patients.

\section{Conclusions}

A 38-year-old female presented to our department with an aggressive chest wall recurrence, as well as with distant metastatic disease, two months following a right modified radical mastectomy for a pathological T3N1a breast cancer. This recurrence was causing extreme pain and distress. As clinical trials have demonstrated an improvement in local control when hyperthermia is used as an adjunct to radiation therapy, our patient was treated with radiation, chemotherapy, and hyperthermia. Local control was achieved, providing her with palliation of her symptoms. This case underscores the importance of considering hyperthermia as part of a multimodality treatment regimen to treat chest wall recurrences.

\section{Additional Information \\ Disclosures}

Human subjects: Consent was obtained by all participants in this study. Conflicts of interest: In compliance with the ICMJE uniform disclosure form, all authors declare the following:

Payment/services info: All authors have declared that no financial support was received from any organization for the submitted work. Financial relationships: All authors have declared that they have no financial relationships at present or within the previous three years with any organizations that might have an interest in the submitted work. Other relationships: All authors have declared that there are no other relationships or activities that could appear to 


\section{Cureus}

have influenced the submitted work.

\section{References}

1. Vernon CC, Hand JW, Field SB, et al.: Radiotherapy with or without hyperthermia in the treatment of superficial localized breast cancer: results from five randomized controlled trials. International Collaborative Hyperthermia Group. Int J Radiat Oncol Biol Phys. 1996, 35:73144. 10.1016/0360-3016(96)00154-X

2. Jones EL, Oleson JR, Prosnitz LR, et al.: Randomized trial of hyperthermia and radiation for superficial tumors. J Clin Oncol. 2005, 23:3079-85. 10.1200/JCO.2005.05.520

3. Franckena M: Review of radiotherapy and hyperthermia in primary cervical cancer . Int J Hyperthermia. 2012, 28:543-48. 10.3109/02656736.2012.670835

4. Rao W, Deng ZS, Liu J: A review of hyperthermia combined with radiotherapy/chemotherapy on malignant tumors. Crit Rev Biomed Eng. 2010, 38:101-16.

10.1615/CritRevBiomedEng.v38.i1.80

5. Kok HP, Crezee J: A comparison of the heating characteristics of capacitive and radiative superficial hyperthermia. Int J Hyperthermia. 2017, 33:378-86.

$10.1080 / 02656736.2016 .1268726$ 